\title{
Radiating Pain
}

National Cancer Institute

\section{Source}

National Cancer Institute. Radiating Pain. NCI Thesaurus. Code C101178.

A sensation of discomfort or distress that spreads from one anatomic location to another. 